\title{
Mild Hypothermia Attenuates the Excitatory Amino Acids Overflow and Diminishes the Nitric Oxide Synthase Activity during Reperfusion after Asphyxial Cardiac Arrest in Rats
}

\author{
S. Hachimi-Idrissi ${ }^{1,3^{*}}$, T. Zgavc ${ }^{2}$, I. Smolders ${ }^{2}$, S. Sarre ${ }^{2}$, L. Huyghens ${ }^{3}$ \\ and Y. Michotte ${ }^{2}$
}

\author{
${ }^{1}$ Emergency Department and Cerebral Resuscitation Research Group of the Ghent \\ University, De Pintelaan, 185, 9000, Ghent, Belgium. \\ ${ }^{2}$ Department of Pharmaceutical Chemistry and Drug Analysis, "Vrije Universiteit Brussel", \\ Laarbeeklaan, 103, B-1090, Brussels, Belgium. \\ ${ }^{3}$ Critical Care Department, and Cerebral resuscitation Research Group of the "Vrije \\ Universiteit Brussel", Laarbeeklaan 103, B-1090, Brussels, Belgium.
}

\section{Authors' contributions}

This work was carried out in collaboration between all authors. Author SH has designed the study, performed the animal preparation and writes the manuscript. The co-authors IS, TZ and SS had performed the microdialysis analysis and help with the statistical analysis and redaction of the manuscript together with authors $Y M$ and $L H$. All the authors had read and approved the final manuscript.

Original Research Article

Received $24^{\text {th }}$ February 2013

Accepted $19^{\text {th }}$ June 2013

Published $19^{\text {th }}$ October 2013

\section{ABSTRACT}

Aims: Neurotransmitter overflow into the extracellular space and activation of nitric oxide synthase were implicated in neuronal death after cerebral ischemia. A small temperature reduction induced after the insult crucially mitigated the neuronal death. To elucidate the mechanisms, dopamine and glutamate as marker of excitatory amino acid (EAA) overflow and the citrulline/arginine ratio (CAR) as marker of nitric oxide synthase were analysed.

Study Design: Animal experiments in rats. 
Place and Duration of the Study: Laboratory of the Department of Pharmaceutical Chemistry and Drug Analysis, Vrije Universiteit Brussel, Brussels between 2001 and 2003.

Methodology: Striatal Glutamate and dopamine and CAR were measured by using microdialysis under normothermic and hypothermic conditions before asphyxial cardiac arrest, during the insult and resuscitation as well as during the weaning process from mechanical ventilation.

Results: After the insult, the EAA overflow increased significantly in the normothermic group. In the hypothermic group, however this overflow was not significantly different from the sham group. The CAR increased up to 5 -fold compared to the basal value in the normothermic group and only 2.5 -fold in the hypothermic group. The brain damage was mitigated in the hypothermic group, while this increased further up 7 days after the insult in the normothermic group.

Conclusion: These results suggest that the neuroprotective effect of mild hypothermia resides in attenuation of the striatal EAA overflow and diminution of the CAR and were associated with a reduction of brain damage at 24 hours and 7 days post insult.

Keywords: Transient global ischemia; citrulline/arginine ratio; excitatory amino acids; nitric oxide synthase and mild hypothermia.

\section{INTRODUCTION}

Brain damage subsequent to ischemia, results from a cascade of interconnected pathological processes, including changes in cerebral blood flow as well as progressive alterations of ion homeostasis and cellular metabolism [1]. During ischemia, the lack of energy to the brain may depolarise neurons, producing a large increase in extracellular neurotransmitters such as glutamate (Glu) and dopamine (DA) [1]. The severity of an ischaemic insult is often defined in terms of its duration, the amount of blood reduction, and the metabolic state of the brain before the insult. A strong correlation between the duration of ischemia and the subsequent degree of neurological impairment has already been demonstrated [2]. In addition, this impairment occurs further after reperfusion [3]. Excitatory amino acids (EAA's) release and free radicals formation such as nitric oxide (NO) mediated further this neuronal damage $[2,3]$.

The release of EAA's causes calcium influx into the cells, and also release of calcium from intracellular stores. The massive increase in intracellular calcium in the ischaemic condition causes activation of proteases, nucleases, phospholipases, nitric oxide synthase (NOS) and leads to cell death $[1,3,4]$.

Increased NO production during reperfusion is an important event in the cascade leading to brain injury [5]. Indeed, the concentration of citrulline (Cit) increased during the post-hypoxic phase in parallel with the increase in EAA's, a finding that is consistent with NO production in the brain secondary to the oxidation of L-arginine (Arg) and the reduction of molecular oxygen [6].

EAA release results in increased NO production and neuronal apoptosis after circulatory arrest in vitro experiments of cell cultures prepared from rats and subjected to either solution containing NMDA or sodium nitroprusside [7]. NO is also produced after direct injection of NMDA into the immature brain, supporting a coupling between NO production and EAA's [8]. 
Furthermore, non-selective NOS inhibition [9] and selective destruction of NOS neurons [10] attenuate brain injury after ischemia as also observed in knockout mice of neuronal NOS [11].

Mild hypothermia $\left(34^{\circ} \mathrm{C}\right)(\mathrm{MH})$ is an established method of neuroprotection when applied before and during an ischaemic insult. Animal and patients studies have indicated that reduction of the brain temperature increases tolerance of the central nervous system to the insult $[12,13,14,15,16]$. The clinical studies have improved the survival and the neurological outcome in witnessed cardiac arrest (CA) displaying a ventricular fibrillation as an initial rhythm $(14,15)$. The both studies has lead to the Advanced Life Support Task Force of the International Liaison Committee on Resuscitation to recommend the use of $\mathrm{MH}$ in unconscious adult patients with spontaneous circulation after an out of hospital CA [17]. The beneficial effects of $\mathrm{MH}$ were originally attributed to a reduction of cerebral metabolic rate [18]. Recently, inhibition of EAA's releases, attenuation of the immune response, or modification of cell death signalling pathways were advocated $[12,13,19]$. It remains however uncertain which mechanisms are particularly involved when $\mathrm{MH}$ is applied after the insult and whether this effect is long lasting.

The purpose of this study was to determine whether $\mathrm{MH}$ induced after the insult and restoration of perfusion could attenuate striatal EAA overflow, and if the citrulline/arginine ratio (CAR) as an assessment of NOS activity could be influenced by $\mathrm{MH}$ in asphyxia cardiac arrest rats. Finally the assessment of the potential effect of $\mathrm{MH}$ remains up to days after the insult.

\section{MATERIALS AND METHODS}

The experiments were conducted in accordance with the National Guidelines on Animal Experiments and were approved by the Ethics Committee for Animal Experimentation of the "Vrije Universiteit Brussel (VUB)", Brussels, Belgium.

\subsection{Experimental Groups}

Male albino Wistar rats weighing 250-300 g were used. All animals underwent surgery 24 hours prior to the experiment. Stereotaxic placement of the microdialysis guide in the striatum was performed under anaesthesia with a mixture of $25 \mathrm{mg} / \mathrm{kg}$ of ketamine and 5 $\mathrm{mg} / \mathrm{kg}$ of diazepam. Coordinates relative to bregma were $A P=+1.2 \mathrm{~mm} ; \mathrm{L}=+2.4 \mathrm{~mm}$; V= -5.8 . Body temperature was kept constant at $37^{\circ} \mathrm{C}$ throughout the surgical procedure by using a heating blanket. The guide was fixed to the skull with dental cement. Immediately after surgery, a CMA/12 microdialysis probe with a 3-mm membrane length (CMA Microdialysis, Stockholm, Sweden) replaced the guide cannula obturator. The probe was continuously perfused with Ringer's solution (147 mM NaCl, $4 \mathrm{mM} \mathrm{KCl}, 1.1 \mathrm{mM} \mathrm{CaCl}$ ) at a flow rate of $2.5 \mu \mathrm{l} / \mathrm{min}$ using a CMA/100 microdialysis pump (CMA Microdialysis, Stockholm, Sweden). The animals were allowed to recover from the surgery overnight and had free access to food and water.

Twenty-four hours after probe positioning, 4 basal dialysates (collections 1 till 4 ) were collected from the striatum of freely moving rats. One other sample was collected after anaesthesia, intubation and ventilation (collection 5), and one other sample was taken after catheterisation and cannulation of the left femoral artery and vein (collection 6). After taking the 6 samples, the rats were randomised in 3 groups: 
- Sham operated group (SG; $n=6$ ): anaesthetised with halothane and $\mathrm{N}_{2} \mathrm{O} / \mathrm{O}_{2}$ $(70 \% / 30 \%)$, had vessel cannulation but no asphyxiation. Controlled ventilation was continued for $120 \mathrm{~min}$.

- Normothermic group (NG; $n=12$ ): under the same anaesthesia and vessel cannulation, had asphyxiation for $8 \mathrm{~min}$, reversed by brief standard external cardiac compression at a frequency of $200 / \mathrm{min}$. Controlled ventilation was continued for 120 $\min$.

- Hypothermic group (HG; $n=12$ ): received the same insult and the same advance life support as described in NG. In contrast to the previous group, after restoration of spontaneous circulation (ROSC), a treatment with $\mathrm{MH}$ was started and maintained for 60 -min post ROSC. Controlled ventilation was continued until 120-min post ROSC.

In the NG and HG, five striatal dialysates were taken during reperfusion (from collections 7 till 11, in $\mathrm{MH}$ group these dialysate were during hypothermia period), followed by 2 dialysates in spontaneously breathing rats after cessation of anaesthesia and ventilation (collections 12 and 13, in MH group after spontaneous warming-up). Accordingly in the SG, 5 striatal dialysates were taken after ventilation and catheterisation, but without insult (collections 7 till 11), followed by 2 striatal dialysates (collections 12 and 13) in spontaneously breathing rats. During anaesthesia and intubation, during catheterisation and during the weaning process from the mechanical ventilation, the probe was still continuously perfused, but the dialysates were discarded (Fig. 1).

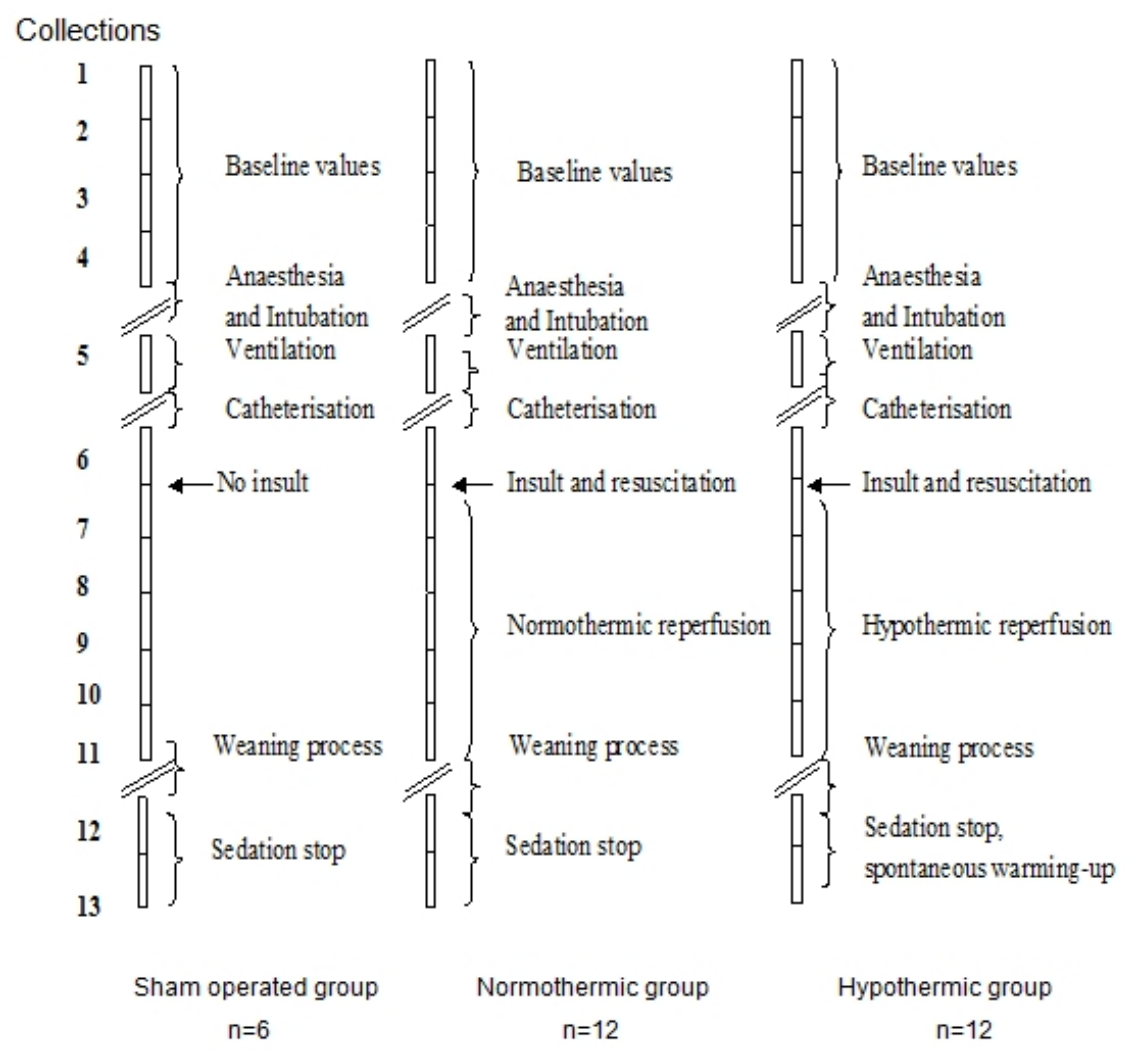

Fig. 1. Study design 


\subsection{Animal Preparation, Insult and Resuscitation}

The rats had free access to food and water before the experiment. Anaesthesia was induced with halothane $3-5 \%$ and $\mathrm{N}_{2} \mathrm{O} / \mathrm{O}_{2}(70 \% / 30 \%)$ insulated into a transparent chamber. After induction, the rat was removed from the chamber, weighed and labelled. The animal was immediately intubated orothracheally with a 14-G plastic catheter under direct laryngoscopy and connected to a ventilator (Harvard, rodent ventilator model 683). Ventilation modalities were a tidal volume of $1 \mathrm{ml} / 100 \mathrm{~g}$, a positive end-expiratory pressure of $3-\mathrm{cm}_{2} \mathrm{O}$ and a frequency of 40 breaths per minute. Ventilation was adjusted to maintain $\mathrm{PaCO}_{2}$ at $30-40$ $\mathrm{mmHg}$, arterial $\mathrm{pH}$ at 7.35-7.45 and $\mathrm{PaO}_{2}>80 \mathrm{mmHg}$.

The rat was then placed on a heating pad and secured to a surgical board with tapes. Electrocardiograph (ECG) limb leads were attached; a tympanic thermistor and a rectal thermometer were placed. The temperature of the rat was controlled with an infrared lamp. A sterile cut-down was performed in the left groin. The left femoral artery and vein were cannulated with a polyethylene 50 catheters.

In NG and HG, stopping mechanical ventilation induced the insult and clamping the tracheal tube at the end of exhalation for $8 \mathrm{~min}$. CA occurred within $3 \mathrm{~min}$ and was defined as a mean arterial blood pressure (MABP) $<10 \mathrm{mmHg}$ without arterial fluctuations. Thus, there was a no-flow period of about 5-min. After 8 min of apnea and airway obstruction, cardiopulmonary resuscitation (CPR) was initiated by unclamping the tracheal tube, restarting mechanical ventilation with $100 \% \mathrm{O}_{2}$ at unchanged tidal volume and at a frequency of 60 inflations $/ \mathrm{min}$. The resuscitation was continued by giving epinephrine $0.01 \mathrm{mg} / \mathrm{kg} \mathrm{IV}$, immediately followed by flushing the catheter with $\mathrm{NaHCO}_{3} 1 \mathrm{mEq} / \mathrm{kg}$ IV and applying sternal compressions (with two fingers) at a rate of $200 / \mathrm{min}$ until ROSC. ROSC was achieved when a spontaneous MABP of $>60 \mathrm{~mm} \mathrm{Hg}$ was obtained. If CPR settings exceeded $2 \mathrm{~min}$, the experiment was considered out of protocol.

In $\mathrm{HG}$, the rats were treated with $\mathrm{MH}$ after ROSC, which was started immediately after ROSC. The mild hypothermia was obtained by lowering the total body temperature to $34^{\circ} \mathrm{C}$ within 8 minutes and was maintained at that level for one hour. $\mathrm{MH}$ was induced by stopping the heating pad and by spraying alcohol on the rat's skin while a fan circulated room air around the animal. The temperature was not allowed to fall below $34^{\circ} \mathrm{C}$. After one hour of $\mathrm{MH}$, the rat was passively and slowly warmed up to $37.5^{\circ} \mathrm{C}$.

The intravascular catheters were removed 120-min post ROSC, the vessels were ligated and the skin closed. Mechanical ventilation was stopped as soon as spontaneous breathing started; the tracheal tube was removed when the breathing frequency exceeded 60 breaths $/ \mathrm{min}$. After extubation, the rat was placed in a chamber with $50 \% \mathrm{O}_{2}$ for $30 \mathrm{~min}$.

\subsection{Sample Analysis}

Sampling periods of 20 min resulted in $50 \mu \mathrm{l}$ dialysates, which were split for the analysis of DA $(20 \mu \mathrm{l}), \mathrm{Arg} / \mathrm{Cit}(15 \mu \mathrm{l})$ and Glu $(15 \mu \mathrm{l})$. DA samples were protected from oxidation by adding $10 \mu \mathrm{l}$ of antioxidant (0.02 $\mathrm{M} \mathrm{HCl}, 0.2 \% \mathrm{Na}$ - metabisulphite; $0.02 \% \mathrm{Na}_{2}$-EDTA).

For the analysis of DA, reversed phase ion-pair microbore liquid chromatography (LC) was used with electrochemical detection [20]. 
For fast Glu analysis, reversed phase microbore LC with gradient elution and fluorescence detection was used. The precolumn derivatization was performed with o-phtalaldehyde/ $\beta$ mercaptoethanol [21].

The determination of Arg and Cit in the microdialysates was based on the method described by Carlberg et al. [21]. The mobile phase consisted of $12.5 \%$ methanol, $12.5 \%$ acetonitrile, $1 \%$ tetrahydrofurane and $74 \% 10 \mathrm{mM} \mathrm{KH}_{2} \mathrm{PO}_{4}$ buffer $\mathrm{pH} 5.9$. A reversed phase microbore LC assay with fluorescence detection was optimised. The microbore column (100 $\mathrm{mm} \times 1$ $\mathrm{mm}$ id.) consisted of $5 \mu \mathrm{m}$ C8 packing (Unijet, Bioanalytical Sytems, West Lafayette, IN). Precolumn derivatization was also performed with o-phtalaldehyde/ $\beta$-mercaptoethanol, as described earlier [22]. The derivatives of Cit and Arg eluted well separated within 8 min following isocratic elution.

\subsection{Histological Investigations}

We carried out two parallel series of experiments ( 5 rats in each group, and 3 groups in each series of experiment), to assess the lesions 24-h and 7 days after the insult by using histological methods. The experimental protocols were the same as in the microdialysis experiments but without a microdialysis probe implanted in the striatum, which allowed the evaluation of the ischemic after the insult per se. In brief, the animals were euthanized with an overdose of Nembutal ${ }^{\circledR}$ and placed in supine position to open the thorax. A catheter was inserted via the apex into the aorta, the right atrium was incised, and saline solution was infused until the perfusate from the right atrium became bloodless. Then, a buffered $4 \%$ formalin solution $\left(\mathrm{NaH}_{2} \mathrm{PO}_{4} \cdot \mathrm{H}_{2} \mathrm{O}\right.$, formaldehyde $\left.40 \%, \mathrm{pH} 7\right)$ was infused. The animals were decapitated immediately after this fixation, and the brain was removed. Before sectioning, the brain was kept for more than $24 \mathrm{~h}$ in the buffered formalin solution. Sections of $100 \mu \mathrm{m}$ thickness were made using a vibratome (MA752 Motorised Advance Vibroslice, Campden Instruments, U.K.). The sections were stained with cresylviolet and were examined by light microscopy. The images of these sections were digitalized with a camera, connected to the microscope and a computer. A computer program $(\mathrm{NIH}$, Image 1.41) quantified the damaged zone on the digital images. The sum of these data resulted in a total volume of damage, expressed as $\mathrm{mm}^{3}$. A technician who was blinded to the treatment category of the rats performed the histological analysis. The histological results at 24 hours were compared to those obtained from surviving rats at 7 days post insult.

\subsection{Statistical Analysis}

The physiological variables were reported as mean \pm standard deviation (SD). Striatal Glu, Arg, and Cit dialysate concentrations were expressed in $\mu \mathrm{M}$. Striatal DA dialysate concentrations were expressed in $\mathrm{nM}$. Values of CAR, Glu and DA in the figures were expressed as mean \pm SD. Data were not corrected for the recovery across the membrane of the microdialysis probes. For determination of statistical differences in neurotransmitter levels over time within one experimental group, the data were analysed with a one-way analysis of variance (ANOVA) for repeated measures and Fisher's protected least significance difference (Fisher PLSD) post hoc tests $(\alpha=0.05)$. The significance of differences between peak dialysate concentrations was determined by the Student's t-test (two-tailed, $\alpha=0.05$ ). The between group comparisons of the CAR were performed at each time point after reperfusion using the Student's test (two-tailed, $\alpha=0.05$ ). The significance of differences between the histological data at 24 hours and at 7 days post insult was also determined by the Student t-test (two-tailed, $\alpha=0.05$ ). 


\section{RESULTS AND DISCUSSION}

\subsection{Physiological Parameters}

The baseline physiological parameters in the 3 experimental groups of rats were similar (Table 1). No difference in body weight, temperature, mean arterial blood pressure or heart rhythm was seen. The results are reported as mean \pm standard deviation (SD).

Table 1. Baseline physiological variables in the 3 groups

\begin{tabular}{llll}
\hline & $\begin{array}{l}\text { Sham operated } \\
\text { group }\end{array}$ & $\begin{array}{l}\text { Normothermic } \\
\text { group }\end{array}$ & $\begin{array}{l}\text { Hypothermic } \\
\text { group }\end{array}$ \\
\hline Number $(\mathrm{n}=)$ & 6 & 12 & 12 \\
Weight at baseline $(\mathrm{gr})$. & $290 \pm 16$ & $298 \pm 17$ & $291 \pm 19$ \\
Temperature $\left({ }^{\circ} \mathrm{C}\right)$ & $37.6 \pm 0.3$ & $37.5 \pm 0.2$ & $37.3 \pm 0.4$ \\
MABP $^{*}(\mathrm{mmHg})$ & $89 \pm 15$ & $91 \pm 18$ & $90 \pm 16$ \\
Heart rate $($ beats $/ \mathrm{min})$ & $355 \pm 23$ & $362 \pm 33$ & $365 \pm 21$ \\
\hline
\end{tabular}

The severity of the anoxic insult in the NG and HG was similar. The time of preparation to asphyxiation, time of asphyxiation to CA, time of CPR to ROSC and the temperature at the end of asphyxiation were similar in both groups. In HG a significant lower tympanic temperature at 10 and 60 min post ROSC was seen as expected according to the protocol (Table 2).

Table 2. Variables parameters in asphyxia cardiac arrest groups (normothermic and hypothermic group)

\begin{tabular}{|c|c|c|}
\hline & $\begin{array}{l}\text { Normothermic } \\
\text { group }\end{array}$ & Hypothermic group \\
\hline Preparation time to start asphyxia (min) & $51 \pm 19$ & $51 \pm 13$ \\
\hline Asphyxial time to CA (sec) & $182 \pm 12$ & $179 \pm 21$ \\
\hline \multicolumn{3}{|l|}{ Temperature $\left({ }^{\circ} \mathrm{C}\right)$} \\
\hline At start of the experiment & $37.5 \pm 0.2$ & $37.3 \pm 0.4$ \\
\hline At end asphyxial $C A^{*}$ & $37.4 \pm 0.2$ & $37.6 \pm 0.1$ \\
\hline At 10 min post ROSC ${ }^{* *}$ & $37.3 \pm 0.2$ & $34.4 \pm 0.2 ¥$ \\
\hline At 60 min post ROSC & $37.6 \pm 0.3$ & $34.1 \pm 0.1 ¥$ \\
\hline External $\mathrm{CPR}^{\star * *}$ time requirement for $\mathrm{ROSC}(\mathrm{sec})$ & $48 \pm 10$ & $49 \pm 7$ \\
\hline
\end{tabular}

\subsection{Time Course Changes in Extracellular Glu, DA and CAR During Reperfusion}

The time-course of striatal changes in Glu overflow in the 3 groups is illustrated in Fig. 2. The basal extracellular levels of Glu before anaesthesia were not statistically different in the 3 groups. The mean baseline values \pm SD were $0.82 \pm 0.16 \mu \mathrm{M}, 0.63 \pm 0.08 \mu \mathrm{M}$ and $0.77 \pm$ $0.16 \mu \mathrm{M}$, respectively in SG, NG and HG. Also, after controlled ventilation and catheterisation no statistical differences in striatal Glu dialysate levels were observed 
between the 3 groups, the mean values \pm SD were $0.75 \pm 0.12 \mu \mathrm{M}, 0.61 \pm 0.08 \mu \mathrm{M}$ and 0.66 $\pm 0.06 \mu \mathrm{M}$, respectively in SG, NG and HG. In the NG, a significant and sustained increase in extracellular striatal Glu concentrations was noticed from 40 minute following the ischaemic insult during reperfusion until the end of the experiment. The maximal level reached was $20.00 \pm 5.15 \mu \mathrm{M}$ (Fig. 2). In HG, slight but not significant increases in Glu concentrations were noticed after ischemia and reperfusion. The maximal increase was observed $40 \mathrm{~min}$ after ROSC reaching the value of $1.99 \pm 2.20 \mu \mathrm{M}$. In the SG the extracellular Glu concentrations remained stable throughout the experiment.

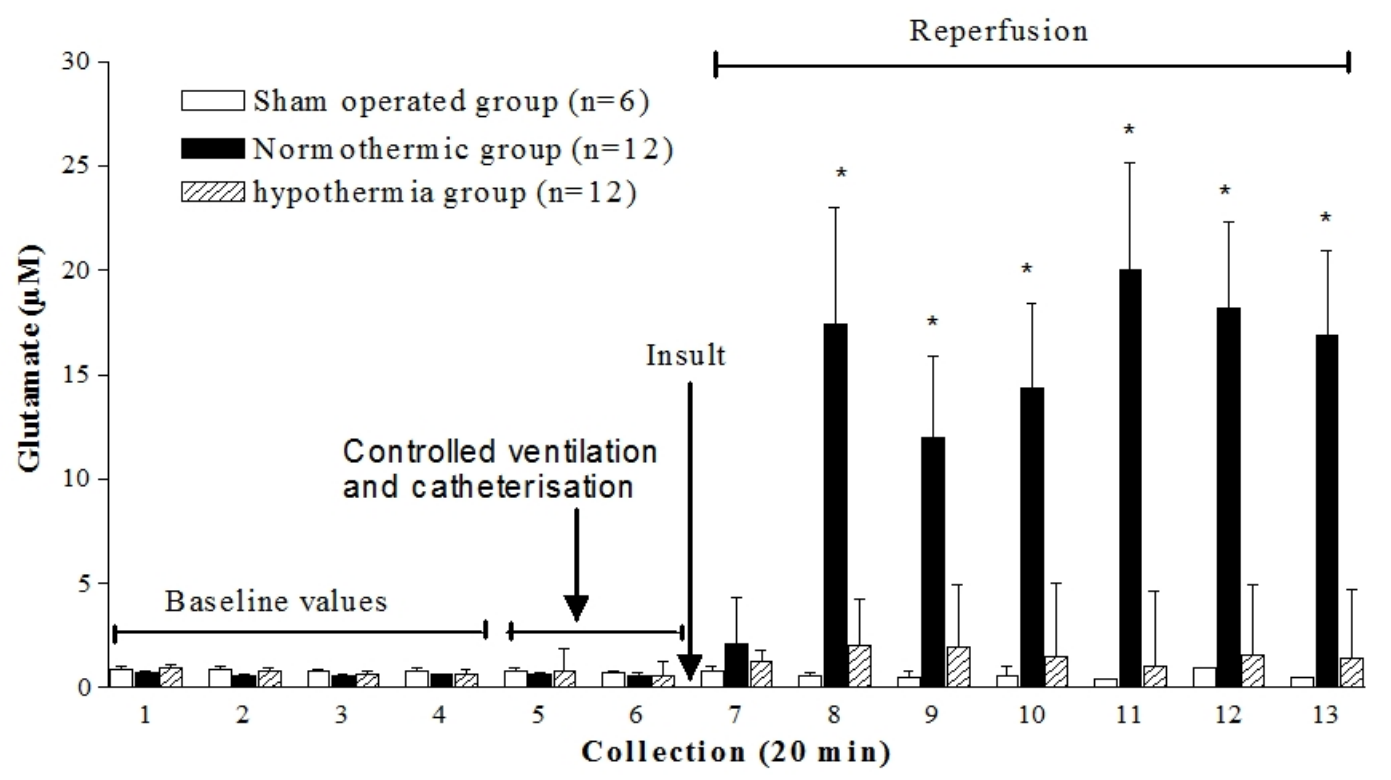

Fig. 2. Time course of glutamate concentration in dialysates from rat striatum, in baseline conditions, during the controlled ventilation and catheterization as well as during the insult and reperfusion in the sham operated group, the normothermic group and in the hypothermic group. The glutamate concentration is expressed in $\mu \mathrm{M}$ as mean \pm SD. Each bar represents a 20 -min collection period. Data were analyzed with one-way ANOVA for repeated measurements followed by Fisher's PLSD post hoc test; asterisks denote values, significantly different from the baseline value $(P \leq 0.05)$

The pattern of DA was similar to that of Glu. The basal values before anaesthesia and after anaesthesia and catheterisation were not statistically different between the 3 experimental groups. The mean basal striatal values of DA \pm SD before anaesthesia were $1.14 \pm 0.18 \mathrm{nM}$, $1.29 \pm 0.14 \mathrm{nM}$ and $1.12 \pm 0.14 \mathrm{nM}$, and after controlled ventilation and catheterisation 0.98 $\pm 0.18 \mathrm{nM}, 1.59 \pm 0.11 \mathrm{nM}$ and $1.07 \pm 0.14 \mathrm{nM}$, respectively in SG, NG and HG. In NG, a significant increases in the extracellular DA concentration was observed 20 min after the ischemic insult, reaching $10.19 \pm 6.9 \mathrm{nM}$. This increase augments further throughout the experiment, reaching a maximum of $96.31 \pm 14.00 \mathrm{nM}$ at time 100-min post ROSC. However, in HG the maximal value was only $2.00 \pm 2.52 \mathrm{nM}$ at 120-min post ROSC; the remaining values were quite similar to those observed in SG (Fig. 3). 


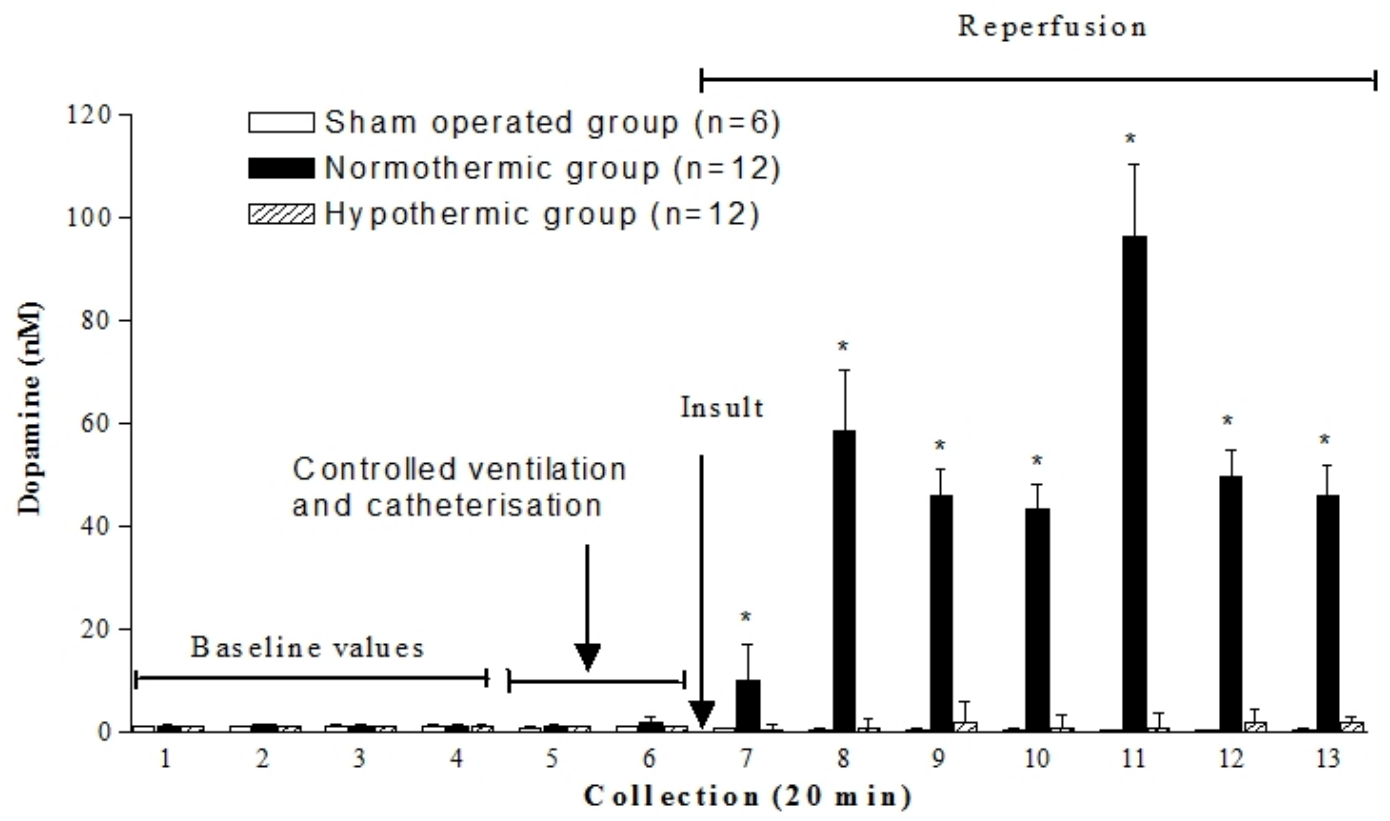

Fig. 3. Time course of dopamine concentration in dialysate from rat striatum, in baseline conditions, during the controlled ventilation and catheterization as well as during the insult and reperfusion in the sham group, the normothermic group and in the hypothermic group. The dopamine concentration is expressed in $\mathrm{nM}$ as mean \pm SD. Each bar represents a 20-min collection period. Data were analyzed with one-way ANOVA for repeated measurements followed by Fisher's PLSD post hoc test; asterisks denote values significantly different from the baseline value $(P \leq 0.05)$

Baseline levels of Arg were $0.330 \pm 0.006 \mu \mathrm{M}, 0.380 \pm 0.003 \mu \mathrm{M}$ and $0.400 \pm 0.007 \mu \mathrm{M}$ respectively in SG, NG and HG. The baseline values of Cit were $0.35 \pm 0.02 \mu \mathrm{M}, 0.39 \pm 0.05$ $\mu \mathrm{M}$ and $0.39 \pm 0.07 \mu \mathrm{M}$ respectively in SG, NG and HG. The CAR increased up to 4 -fold after ROSC till up to 5 fold at the end of the experiment in the NG. In the HG a maximum increase of 2.5-fold compared to the basal value was seen $60 \mathrm{~min}$ after ROSC decreasing gradually to the basal values at the end of the experiment. In SG the CAR remained about 1 throughout the experiment (Fig. 4). 


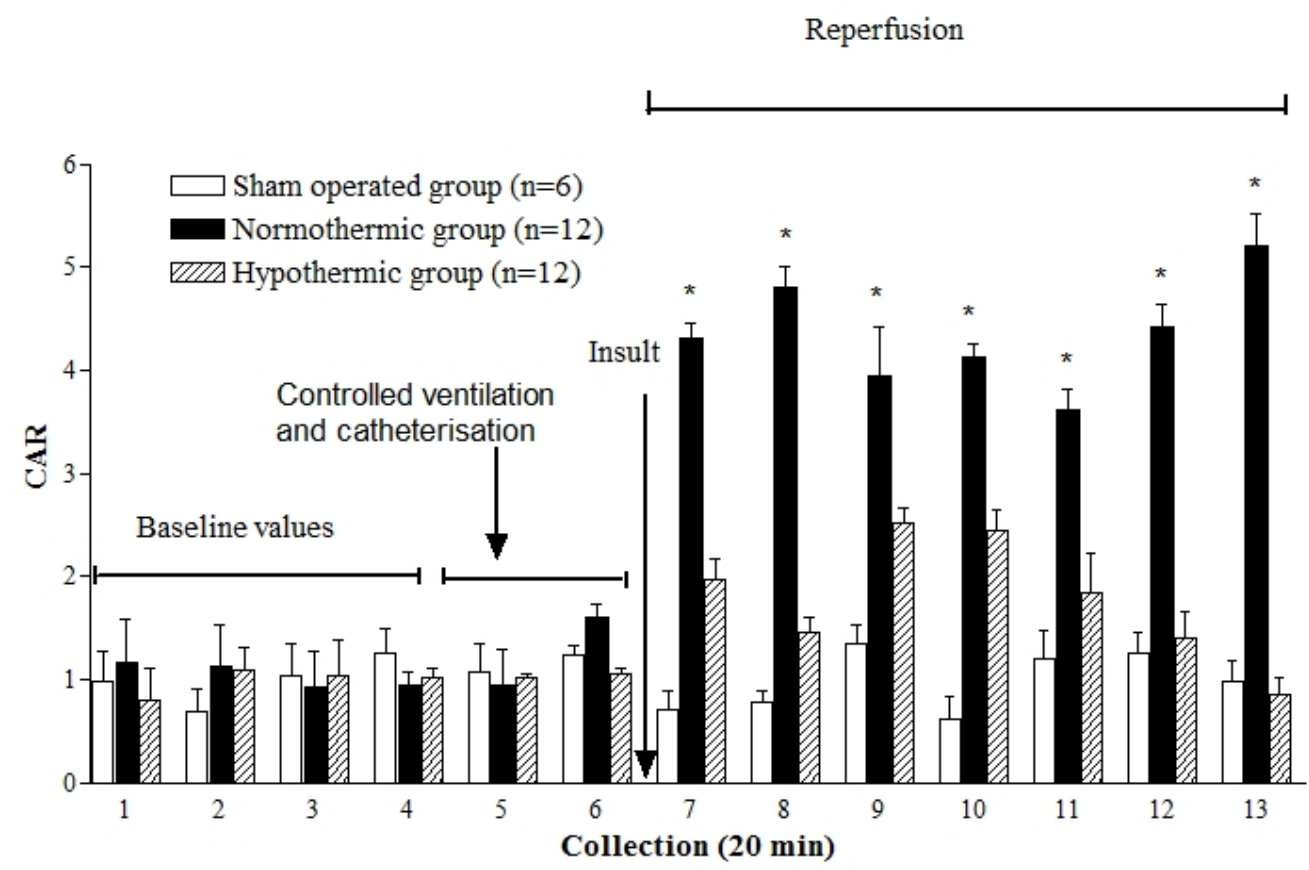

Fig. 4. Time course of the mean citrulline/arginine ratio (CAR) $\pm S D$ in dialysates from rat striatum, in baseline conditions, during the controlled ventilation and catheterization as well as during the insult and reperfusion in the sham operated group, the normothermic group and the hypothermic group. Each bar represents a 20min collection period. Data were analyzed with one way ANOVA for repeated measurements followed by Fisher's PLSD post hoc test; asterisks denote values significantly different from the baseline value $(P \leq 0.05)$

\subsection{Histological Data}

Histological data's were carried out a series of rats, which were subjected to the same insult and resuscitations manoeuvres, and depicted similar physiological parameters (data not shown). Only the rats that survive the whole procedure were analysed.

Coronal slices $(100 \mu \mathrm{m})$ were stained with Cresyl violet. The brain damage was defined as poorly stained areas. In the NG, the brain showed multiple and large poor staining areas in both hemispheres. The damaged brain was significantly higher in NG 24 hours post insult. The percentage of brain damage was $18.7 \%, 4 \%$ and $0 \%$ respectively in the NG, HG and SG.

At 7 days post insult, the brain damage was also significantly higher in NG than in HG. The percentage was $24.4 \%, 3.7 \%$ and $0 \%$ respectively in NG, HG and SG. When comparing in NG the brain damage measured at 24 hours and at 7 days post insult, a significant difference $(p<0.05)$ was noticed. However in HG, no statistical difference between the percentage of brain damage at 24 hours and 7 days post insult was noticed (Fig. 5). 


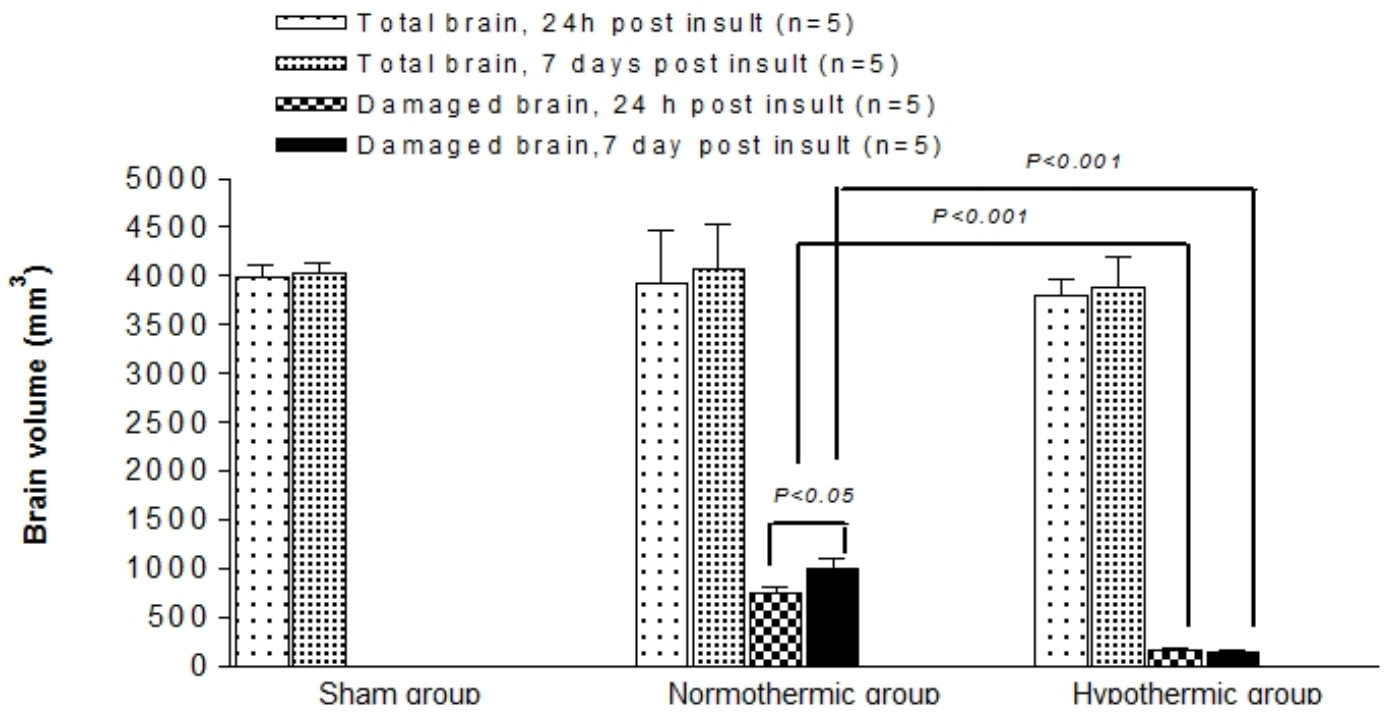

Fig. 5. Total brain volume and damaged brain 24 hours and 7 days post insult in the sham operated group $(n=5)$, the normothermic group $(n=5)$ and the hypothermic group $(n=5)$. The volume is expressed as $\mathrm{mm}^{3}$ (mean $\pm S D$ ). The significance of difference between the histological data at 24 hours and 7 days postinsult was determined by the Student t-test (Two-tailed, $P \leq 0.05$ )

$\mathrm{MH}$ induced after the ischemic insult and recovery of perfusion attenuated the DA and Glu overflow in rat's striatum. CAR derived from striatal citrulline and arginine ratio at each collection time, increased during reperfusion after normothermic resuscitation, and $\mathrm{MH}$ diminished this ratio. Moreover, $\mathrm{MH}$ reduced the brain damage 24 hours and 7 days post insult.

In normothermic conditions, cerebral anoxia induces a surge in the extracellular levels of EAA's that has been implicated in ischaemic neuronal damage [23]. These observations are in accordance with our data from rat striatum in NG after asphyxial CA.

During ischemia, the extracellular Glu concentration is excessively increased [24]. It has been suggested that this increase of Glu produces brain injury by its neurotoxicity [25]. A reduction in brain temperature inhibits the post-ischemic brain injury [26]. Whether this neuroprotective effect is secondary to the reduction of ischemia induced Glu overflow [23] or not [27] is still unclear. In our study, the post insult $\mathrm{MH}$ was associated with a marked attenuation of striatal Glu concentration and reduction of brain damage.

In addition, there is some evidence, that during reperfusion after an ischemic insult, Glu may stimulate other neurotransmitter release such as DA $[2,28]$, which in turn can inhibit Glu uptake [29]. Moreover, the neurotoxicity of DA can also be found in DA itself, as well as its metabolic by-products, e.g. quinones. Indeed, DA is easily oxidised, both via monoamine oxidase (MAO), and by molecular oxygen. Thus, DA may generate potentially neurotoxic oxygen free radicals, which can lead to neuronal death [30]. In our study, $\mathrm{MH}$ induced after the insult drastically attenuated the release of DA. Normothermic resuscitation showed, however, a marked increase in DA release during reperfusion. 
Stoichiometric consumption of Arg and synthesis of Cit accompany NO production. Therefore, it is reasonable to assume that the CAR could be used as a surrogate marker to assess the NOS activity and NO production $[8,31,32]$. The validity of this approach depends on the assumption that Cit is synthesised in the brain only by NOS and not by ornithine transcarbamoylphosphate synthase (OTC), as it occurs in some peripheral organs. In this regard, it is important to mention that OTC is not present in the brain tissue [33]. We clearly demonstrated in this study that CAR could be used as an assessment of NOS during normothermic reperfusion after asphyxial CA.

There are several reports concerning the changes in NO synthesis following cerebral ischemia: Thorensen et al. [32] using microdialysis techniques studied the evolution of CAR during reperfusion after 45 min hypoxic insult in rat; Kader et al. [34] measured nitrite levels by a fluorimetric method; Tominaga et al. [35] investigated NO production by a paramagnetic resonance NO-trapping technique; Malinski et al. [36] and Lin et al. [37] by using a NOsensitive microsensor implanted in rat brain, measured the NO concentration immediately after middle cerebral occlusion. All these studies demonstrate that the NO production increases during focal ischemia and hypoxia. Only in the study of Kirkerby et al. [38] a decrease of NO concentration during hypoxia was reported. These conflicting data could be related to the short time of the insult. In our study, in which global ischemia secondary to asphyxial CA was involved, CAR increased during reperfusion and showed that $\mathrm{MH}$ induced after the insult attenuated this ratio.

The study of Tan et al. [6] and Globus et al. [39] showed that persistent levels of EAA after reperfusion induce brain damage in animals. Moreover, the inability to normalise the levels of EAA's after hypoxia-ischemia in adult and new-born rats and in piglets was associated with subsequent brain injury $[32,40]$.

In the present study, $\mathrm{MH}$ induced only after the insult clearly attenuated the efflux of striatal Glu and DA, and diminished CAR. However, we were still unable to completely normalize the histology of the brain. This could be explained by the fact that $\mathrm{MH}$ was unable to fully normalise the NOS activity and therefore the NO production might still be high enough to induce some cerebral damage.

In adult animals, conflicting results exist concerning long-term protection by hypothermia. Dietrich et al. [41] concluded that the benefit of posthypoxic hypothermia might increase the therapeutic time window, allowing other therapeutic strategies in the post insult period. In adult male rats, they found that post hypoxic hypothermia neuroprotection was significant after 3 days of survival, detectable after 7 days but disappeared after 2 months; hence they concluded that hypothermia merely postponed the damage. According to a study in newborn rats [42] and piglets [43], it has further been suggested that post-hypoxic hypothermia is only protective against moderate and not against severe damage. This view is also supported by a clinical study of head trauma [44], demonstrating that patients with severe head trauma had no improvement at 6 months follow-up after 24 hours of mild hypothermia. In other animals $[45,46]$ and human studies $[15,16]$, the post-hypoxic hypothermia was able to protect the brain for a long period of time both from mild and severe insults. In our study, histological analysis was performed at 24 hours and at 7 days post ROSC. This particular time point was taken from our previous study; in which the cerebral maturation was reached at 7 days post ROSC [47]. MH induced after ROSC was able to protect the brain at 24 hours and at 7 days, while in the NG, the cerebral damage was significantly higher than in SG and HG at 24 hours. The damage seen in the NG increased further at 7 days post ROSC, 
respectively from $18.7 \%$ to $24.4 \%$. This detrimental consequence of normothermic resuscitation could be explained by the secondary inflammatory response, which leads to neuronal death [48].

\section{LIMITATIONS OF THE CURRENT METHOD FOR ASSESSING THE NOS ACTIVITY}

We believe that is fair to note that the lack of straightforward, reliable method of assessing the NOS activity still confounds our progress in this field. Our current method remains somewhat primitive and unsatisfactory to identify the NOS activity and only focusing on the small part of the brain (striatum). Still, since comparing striatal dialysates data obtained from the SG, NG and HG, the potential changes observed in the NG compared to the SG may be related to the insult, resuscitation and reperfusion, and since $\mathrm{MH}$ diminishes this ratio, we may conclude that $\mathrm{MH}$ reduces this ratio and may therefore be able to mitigate brain damage.

To advance our understanding and to develop new therapies, better methods of measuring NO activity should be prioritized and developed. These may include the use of the chemiluminescence or nitrite/nitrate levels or even transgenic animals that allow better measurement and understanding of the mechanisms that occur during the insult, resuscitation and the reperfusion after $\mathrm{CA}$. Moreover these beneficial effects of $\mathrm{MH}$ should be confirmed in high phylogenetic species.

\section{CONCLUSION}

This study demonstrates that CAR could be used as a surrogate marker of NOS activity after asphyxial $\mathrm{CA}$ and that $\mathrm{MH}$ induced after the insult normalised the extracellular striatal efflux of Glu and DA and lowered the CAR. These findings may be important in the understanding of the pathophysiological mechanisms of brain damage after asphyxial CA, and emphasise the beneficial effects of $\mathrm{MH}$ induced upon restoration of reperfusion.

\section{CONSENT}

Not applicable.

\section{ETHICAL APPROVAL}

All authors hereby declare that all experiments have been examined and approved by the appropriate ethics committee and have therefore been performed in accordance with the ethical standards laid down in the 1964 Declaration of Helsinki.

\section{COMPETING INTERESTS}

All authors acknowledge that they have no financial or personal relationships with other people or organisations that could inappropriately influence or bias this work.

\section{REFERENCES}

1. Siesjö BK. Pathophysiology and treatment of focal cerebral ischemia, Part II: Mechanisms and drug treatment. J. Neurosurg. 1992;77:1247-52. 
2. Baker AJ, Zornow MH, Yaksh TL, Skilling SR, Smullin DH, Larson AA, Kuczenski R. Changes in extracellular concentrations of glutamate, aspartate, glycine, dopamine, serotonine, and dopamine metabolites after transient global ischaemia in the rabbit brain. J. Neurochem. 1991;57:1370-79.

3. Tseng EE, Brock MV, Lange MS, Blue ME, Troncoso JC, Kwon CC, Lowenstein CJ, Johnston MV, Baumgartner WA. Neuronal nitric oxide synthase inhibition reduces neuronal apoptosis after hypo- thermic circulatory arrest. Ann Thorac Surg. 1997;64:1639-47.

4. Nitatori T, Sato N, Waguri S, Karasawa Y, Araki H, Shibanai K, Komonami E, Uchiyama Y. Delayed neuronal death in the CA1 pyramidal cell layer of the gerbil hippocampus following transient ischaemia is apoptosis. J. Neurosci. 1995;15:100111.

5. Johnston MV, Treacher WH, Taylor CA. Hypoxic and ischemia central nervous disorders in infants and children. Adv. Pediatr. 1995;42:1-45.

6. Tan WKM, Williams CE, During MJ, Mallard CE, Gunning MI, Gunn AJ, Gluckman PD. Accumulation of cytotoxins during the development of seizures and edema after hypoxic-ischemic injury in late gestation fetal sheep. Pediatr. Res. 1996;39:791-7.

7. Dawson VL, Dawson TM, Bartley DA, Uhl GR, Snyder SH. Mechanisms of nitric oxidemediated neurotoxicity in primary brain cultures. J. Neurosci. 1993;13: 2651-61.

8. Northington FJ, Tobin JR, Koehler RC, Traystman RJ. In vivo production of nitric oxide correlates with NMDA-induced cerebral hypermia in newborn sheep. Am. J. Physiol. 1995;269:215-21.

9. Trifiletti RR. Neuroprotective effects of NG-nitro-L-arginine in focal stroke in the 7-day old rat. Eur. J. Pharmaco. 1992;21:197-8.

10. Ferriero DM, Sheldon RA, Black SM. Chuai J. Selective destruction of nitric oxide synthase neurons with quisqualate reduces damage after hypoxia-ischemia in the neonatal rat. Pediatr. Res. 1995;38:912-8.

11. Ferriero DM, Holtzman DM, Black SM, Seldon RA. Neonatal mice lacking neuronal nitric oxide synthase are less vulnerable to hypoxic-ischemic injury. Neurobiol. Dis. 1996;3:364-71.

12. Zhao H, Steinberg GK, Sapolsky RM. General versus specific actions of mildmoderate hypothermia in attenuating cerebral ischemic damage. J Cereb Blood Flow Metab. 2007;27:1879-94.

13. Xu L, Yenari MA, Steinberg GK, Giffard RG. Mild hypothermia reduces apoptosis of mouse neurons in vitro early in the cascade. J Cereb Blood Flow Metab. 2002;22:218.

14. Bernard SA, Gray TW, Buist MD, Jones BM, Silvester W, Gutteridge G, Smith K. Treatment of comatose survivors of out-of-hospital cardiac arrest with induced hypothermia. N Engl J Med. 2002;346:557-63.

15. HACA. Study Group Mild therapeutic hypothermia to improve the neurological outcome after cardiac arrest. The hypothermia after Cardiac Arrest Study Group. N Engl J Med. 2002;346:549 - 56.

16. Holzer M, Bernard S, Hachimi-Idrissi S, Roine R, Sterz F, Mülner M. Hypothermia for neuroprotection after cardiac arrest: systematic review and individual patient data meta-analysis. Critical Care Medicine. 2005;33:414-8.

17. Nolan JP, Morley PT, Hoek TL, Hickey RW. Advancement Life support Task Force of the International Liaison committee on Resuscitation. Therapeutic hypothermia after cardiac arrest. An advisory statement by the Advancement Life support Task Force of the International Liaison committee on Resuscitation. Resuscitation. 2003;57:231-5.

18. Michenfelder J, Theye R. Hypothermia: effect on canine brain and whole body metabolism. Anesthesiology. 1968;29:1107-12. 
19. Meybohm P, Gruenewald M, Albrecht M, Zacharowski KD, Lucius R, et Zitta K, Koch A, Tran N, Scholz J, Bein B. Hypothermia and postconditioning after cardiopulmonary resuscitation reduce cardiac dysfunction by modulating inflammation, apoptosis and remodeling. PLoS One. 2009;4:e7588.

20. Smolders I, Sarre S, Vanhaesendonck C. Ebinger G, Michotte Y. Extracellular striatal dopamine and glutamate after decortication and kainate receptor stimulation, as measured by microdialysis. J. Neurochem. 1996;66:2373-80.

21. Smolders I, Sarre S, Ebinger G, Michotte Y. The analysis of excitatory, inhibitory and other amino acids in rat brain microdialysates using microbore liquid chromatography. J. Neurosci. Meth. 1995;57:47-53.

22. Carlberg M. Assay of neuronal nitric oxide synthase by HPLC determination of citrulline. J. Neurosci Methods. 1994;52:165-7.

23. Mitani A, Kataoka K. Critical levels of extracellular glutamate mediating gerbil hippocampal delayed neuronal death during hypothermia: brain microdialysis study. Neuroscience. 1991;42: 661-70.

24. Bogaert L, Scheller D, Moonen J, Sarre S, Smolders I, Ebinger G, Michotte Y. Neurochemical changes and laser doppler flowmetry in the endothelin-1 rat model for focal cerebral ischemia. Brain. Res. 2000;887:268-77.

25. Rothman SM, Olney JW. Glutamate and the patholophysiology of hypoxic- ischemic brain damage. Ann. Neurol. 1986;19:105-11.

26. Minamisawa $\mathrm{H}$, Nordström $\mathrm{CH}$, Smith $\mathrm{ML}$, Siesjö BK. The influence of mild body and brain hypothermia on ischemic brain damage. J. Cerebr. Blood Flow Metab. 1990;10:365-74.

27. Yamamoto H, Mitani A, Cui Y, Takechi S, Irita J, Suga T, Arai T, Kataoka K. Neuroprotective effect of mild hypothermia cannot be explained in terms of a reduction of glutamate release during ischemia. Neuroscience. 1999;91:501-9.

28. Lonart G, Zigmond MJ. High Glutamate concentrations evoke $\mathrm{Ca}^{2+}$ independent dopamine release from striatal slices: a possible role of reverse dopamine transport. J. Pharmacol. Exp. Ther. 1991;256:1132-8.

29. Kerkerian L, Dusticier N, Nieoullon A. Modulatory effect of dopamine on high affinity glutamate uptake in the rat striatum. J. Neurochem. 1987;48:1301-6.

30. Fornstedt B. Role of cathecolamine auto-oxidation in the degeneration of dopamine neurons. Acta Neurol. Scand. 1990;90:12-4.

31. Brock MV, Blue ME, Lowenstein CJ, Northington FA, Johnston MV, Baumgartner WA. Induction of neuronal nitric oxide after hypothermic circulatory arrest Ann. Thorac. Surg. 1996;62:1313-20.

32. Thorensen $M$, Satas $S$, Puka-Sundvall $M$, Whitelaw A, Hallström Ä, Loberg EM, Ungerstedt $U$, Steen PA, Hagberg $H$. Post-hypoxic hypothermia reduces cerebrocortical release of NO and excitotoxins. Neuro Report. 1997;8:3359-62.

33. Eliasson MJ, Blackshaw S, Schell MJ, Snyder SHNeuronal nitric oxide synthase alternatively spliced forms: prominent functional localisation in the brain. Proc. Natl. Acad. Sci. 1997;94:3396-401.

34. Kader A, Frazzini VI, Baker CJ, Solomon RA, Trifiletti RR. Effect of mild hypothermia on nitric oxide synthesis during focal cerebral ischemia. Neurosurgery. 1994;35:272-7.

35. Tominaga T, Sato S, Ohnishi T, Ohnishi ST. Electron paramagnetic resonance (EPR) detection of nitric oxide produced during forebrain ischemia of the rat. J. Cereb. Blood Flow Metab. 1994;14:715-22.

36. Malinski T, Bailey F, Zhang ZG., Chopp M. Nitric oxide measured by a porphyrinic microsensor in rat brain after transient middle cerebral artery occlusion. J. Cereb. Blood Flow Metab. 1993;13:355-8. 
37. Lin SZ, Chiou AL, Yang Y. Ketamine antagonises nitric oxide release from cerebral cortex after middle cerebral artery ligation in rats. Stroke. 1996;27:747-52.

38. Kirkeby OJ, Kutzsche S, Risöe C, Rise IR. Cerebral nitric oxide concentration and microcirculation during hypercapnia, hypoxia, and high intracranial pressure in pigs. J. Clin Neurosci. 2000;7:531-8.

39. Globus MYT, Ginsberg MD, Busto R. Excitatory index- a biochemical marker of selective vulnerability. Neurosci. Lett. 1991;127:39-42.

40. Puka-Sundvall $M$, Sandberg $M$, Hagberg $H$. Brain injury after hypoxia-ischemia in newborn rats: relation to extracellular levels of excitatory amino acids and cysteine. Brain Res. 1997;750:325-8.

41. Dietrich WD, Busto R, Alonso O, Globus MYT, Ginsberg MD. Intraischemic but not postischemic brain hypothermia protects chronocally following global forebrain ischemia in rats. J. Cereb. Blood Flow Metab. 1993;13:541-9.

42. Trescher $\mathrm{WH}$, Ishiwa S, Johnston MV. Brief post-hypoxic-ischemic hypothermia markedly delays neonatal brain injury. Brain Dev. 1997;19:326-38.

43. Haaland K, Loberg EM, Steen PA, Thorensen M. Posthypoxic hypothermic in newborn piglets. Pediatr. Res. 1997;41:505-12.

44. Clifton GL, Miller ER, Choi SC, Levin HS, McCauley S, Smith KR Jr, Muizelaar JP, Wagner FC Jr, Marion DW, Luerssen TG, Chesnut RM, Schwartz M. Lack of effect of induction of hypothermia after acute brain injury. N Engl J Med. 2001;344:556-63.

45. Bona E, Hagberg H, Loberg EM, Bagenholm R, Thorensen M. Protective effects of moderate hypothermia after neonatal hypoxia-ischemia: short and long term outcome. Pediatr. Res. 1998;43:738-45.

46. Thoresen M, Bagenholm R, Loberg EM, Apricena F, Kjellmer I. Post hypoxic cooling of neonatal rats provides protection against brain injury. Arch. Dis. Child. 1996;74:3-9.

47. Hachimi-Idrissi S, Corne L, Huyghens L. The effect of mild hypothermia and induced hypertension on long term survival rate and neurological outcome after asphyxial cardiac arrest in rats. Resuscitation. 2001;49:73-82

48. Dietrich WD, Busto R, Bethea JR. Postischemic hypothermia and IL10 treatment provide long-lasting neuroprotection of CA1 hippocampus following transient global ischemia in rats. Exp. Neurol. 1999;158:444-50.

(c) 2014 Hachimi-Idrissi et al.; This is an Open Access article distributed under the terms of the Creative Commons Attribution License (http://creativecommons.org/licenses/by/3.0), which permits unrestricted use, distribution, and reproduction in any medium, provided the original work is properly cited.

\section{Peer-review history:}

The peer review history for this paper can be accessed here: http://www.sciencedomain.org/review-history.php?iid=298\&id=12\&aid=2288 